\title{
Metodología para la elaboración de Pellets con subproductos de Café y Cacao
}

\section{Methodology for Pellets building with Coffee and Cocoa derlvates}

\section{Die Methodik der verarbeitung von Pellets als nebenprodukte con Kaffee und Kakao}

\author{
Nelson Gutiérrez Guzmán ${ }^{1}$, José Dubán Henao Cuéllar², Oscar Mauricio Oviedo Ramírez ${ }^{3}$
}

\section{Resumen}

Este artículo presenta la metodología para la elaboración de dos tipos de alimentos, que incluyen en su formulación subproductos generados en el beneficio del café y cacao, con potencial uso para la alimentación de conejos en las etapas de ceba y cría; se utilizó una proporción de $50 \%$ en cáscara de cacao, $40 \%$ de concentrado comercial (CONTEGRAL ${ }^{\circledR}$ ) y $10 \%$ de harina de maíz para el alimentoT1, mientras que para el alimento T2 se utilizó pulpa de café al 50\%, 40\% de concentrado comercial (CONTEGRAL ${ }^{\circledR}$ ) y $10 \%$ de harina de maíz; Se obtuvieron dos tipos de concentrados estables, de características físicas similares al del concentrado comercial, indicando que el procedimiento definido en esta investigación satisface los requerimientos, sin embargo, se presentan diferencias notorias en color, de acuerdo a las coordenadas colorimétricas encontradas; cabe destacar que el alimento $\mathrm{T} 2$, presenta un color más oscuro que los otros dos alimentos; los parámetros físicos evaluados no mostraron diferencias estadísticamente significativas.

Palabras claves: pellets, subproductos de café y cacao.

\begin{abstract}
This paper shows the methodology for the making of two types of food which include in its making derivates that come from coffee and cocoa, with a potential use for rabbits feeding in its breeding phase. It was used a proportion of: $50 \%$ of cocoa shell, $40 \%$ of

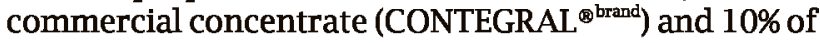
cornmeal for the T1 food, and for the T2 food it was used coffee pulp at 50\%, 40\% of commercial concentrate (CONTEGRAL ${ }^{\text {brand }}$ ) and 10\% of cornmeal. We got two types of solid concentrates as a result, with similar features as the commercial concentrate showing that the defined procedure in this research satisfies the requirements. Nevertheless, some notorious differences in color showed up, according to the color-metric coordinates found. It is noteworthy that the type of food T2 shows a darker color than the other two types of food. The physical parameters assessed didn't show any statistically significant differences.
\end{abstract}

Keywords: Pellets, Coffee and cocoa derivate

\section{Zusammenfassung}

Dieser Artikel beschreibt die Methode der Herstellung von zwei Arten von Lebensmitteln und den Nebenprodukten, welche bei der Gewinnung von Kaffee und Kakao erzeugt werden und potenziell für die Ernährung von Kaninchen während der Mast und Aufzucht verwendet werden könnten. Im Versuch mischte man ein Verhältnis von $50 \%$ Kakaoschalen, $40 \%$ eines kommerziellen Konzentrats (CONTEGRAL ${ }^{\circledR}$ ) und 10\% Maismehl für das Futtermittel T1, während man für das Futtermittel T2 50\% Fruchtfleisch der Kaffeekirschen, 40\% des kommerziellen Konzentrats (CONTEGRAL ${ }^{\star}$ ) und 10\% Maismehl verwendete. Man erhielt zwei Typen eines stabilen Konzentrats mit ähnlichen physikalischen Eigenschaften wie bei dem kommerziellen Konzentrat. Dies zeigt, dass das in dieser Untersuchung festgelegte Verfahren die Anforderungen erfüllte, jedoch wiesen die Konzentrate deutliche Unterschiede in der Farbe, gemäß der vorgefundenen farbmesstechnischen Koordinaten, auf. Besonders hervorzuheben ist hier das Futtermittel T2, welches eme viel dunklere Farbe aufwies, als die anderen Futtermittel. Die ausgewerteten physikalischen Parameter zeigten allerdings keine signifikanten statischen Abweichungen.

1 - Doctor en tecnología de alimentos. Universidad Surcolombiana. Neiva. Colombia.ngutierrezg@usco.edu.co

2 - Doctor en ingeniería agrícola. Universidad Surcolombiana. Neiva. Colombia. duvanhenao23@hotmail.com

3 - Ingeniero Agrícola. Hidratec Ingeniería S.A.S. oscaroviedo@hidratecing.com 


\section{Introducción}

La cría de conejos constituye una alternativa económica para fami-empresas rurales, en pequeñas áreas se pueden establecer instalaciones caseras de producción a bajos costos con materiales propios de la finca. Tradicionalmente se utiliza en la alimentación de conejos residuos propios de la alimentación humana y plantas herbáceas, pensando en disminuir los costos ocasionados por la utilización de alimentación balanceada.

Diferentes estudios se han realizado sobre la utilización de alimentos balanceados que llevan dentro de su formulación materias primas no convencionales, como es el caso de Nieves, Cordero, Teran y González. (2004), quienes utilizaron diferentes proporciones de Follaje Morera en alimentación de conejos destetados; Nieves, López y Cadena (2001), evaluaron conejos de engorde con dietas basadas en materias primas no convencionales, Quintero, García y Peláez (2007) utilizaron suplementos de una hierba rústica conocida como botón de oro en alimentación de conejos Nueva Zelanda en fase de crecimiento; y Veloz (2011), quien estudió la utilización de diferentes niveles de harina de algas de agua dulce en la alimentación de conejos californianos. La pulpa de café como suplemento para la alimentación animal, ha sido investigada por Bautista, Molina y Rodríguez (1999), en alimentación de conejos, y por Bautista, Pernia, Barrueta y Useche (2005), en la alimentación de alevines de cachama; mientras que la utilización de cáscara de cacao en la alimentación animal no ha sido reportada.

La forma y el tamaño de la partícula en el alimento para animales, son características importantes en la dieta de las especies menores, Ciprian e Hidalgo (2007) reportaron que el tamaño de la partícula afecta la velocidad del tránsito del alimento por el tracto digestivo, afectando el tiempo total de la digestión, por lo que Sánchez (2002), recomienda la elaboración de pellets o gránulos para conejos, con diámetros entre 2,5 y $4 \mathrm{~mm}$, y entre 5 y $8 \mathrm{~mm}$ de longitud.

En este trabajo se presenta la metodología para la elaboración de dos tipos de pellets formulados con subproductos generados en el beneficio del café y cacao, con potencial uso para la dieta de conejos; se realizó una caracterización física en el producto formulado y se comparó el color final de los tres tipos de alimentos evaluados.

\section{Metodología}

La materia prima tanto de pulpa de café como cáscara de cacao se obtuvo de la Finca Coralito ubicada a 5 minutos del casco urbano del municipio de la PlataHuila, Colombia, en la vereda Bajo Cañada, una vez beneficiados estos subproductos se lavaron por separado, posteriormente la pulpa de café se prensó con el fin de extraer la mayor cantidad de humedad, lixiviados y disminuir el tiempo de secado; por otra parte la cáscara de cacao se cortó en trozos para disminuir el tiempo de secado; Para la elaboración del alimento se deshidrataron por separado, en un secador solar, tanto la pulpa de café como los trozos de cáscara de cacao hasta $10 \%$ de humedad base húmeda (Hbh) aproximadamente; la trituración de la pulpa de café, la cáscara de cacao y el concentrado con contenidos de humedad de 9,6\%, 9,5\% y 6,9\% respectivamente, se realizó en un molino casero impulsado por motor de potencia $0,5 \mathrm{Hp}$,una vez molidas las materias primas por separado, se pasaron por tamiz $\mathrm{N}^{\circ} 20$, para garantizar que el diámetro de la partícula sea inferior de tal manera que permitala absorción de agua fácilmente y mejore su propiedad mecánica plástica para el peletizado.

Para la elaboración de los pellets se mezclaron en proporciones de $50 \%$ de cáscara de cacao, $40 \%$ concentrado comercial molido y $10 \%$ harina de maíz para $\mathrm{T} 1 ; 50 \%$ de pulpa de café, $40 \%$ concentrado comercial molido y $10 \%$ harina de maíz para T2 (Tabla 1), en cada tratamiento se realizaron tres repeticiones.

Tabla 1. Composición final de los alimentos para T1 y 2 .

\begin{tabular}{|l|l|l|l|}
\hline \multirow{4}{*}{ T1 } & Componente & $\begin{array}{l}\text { Peso } \\
(\mathbf{g r})\end{array}$ & $\mathbf{( \% )}$ \\
\hline \multirow{4}{*}{ Tás } & Cáscara de Cacao & 500 & 50 \\
\cline { 2 - 4 } & Concentrado & 400 & 40 \\
\cline { 2 - 4 } & Harina de Maíz & 100 & 10 \\
\cline { 2 - 4 } & Total & 1000 & 100 \\
\hline \multirow{4}{*}{ T2 } & Cáscara de Café & 500 & 50 \\
\cline { 2 - 4 } & Concentrado & 400 & 40 \\
\cline { 2 - 4 } & Harina de Maíz & 100 & 10 \\
\cline { 2 - 4 } & Total & 1000 & 100 \\
\hline
\end{tabular}

Para la elaboración de lo pellets se mezclaron los componentes y se humedecieron con una solución de agua y melaza a 50 grados Brix, hasta obtener una contextura homogénea, posteriormente se pasaron por un dispositivo de peletización manual (Fig. 1), construido en plástico de alta dureza, con diámetro interno $2,88 \mathrm{~cm}$ con reducción a $0,60 \mathrm{~cm}$. en la salida, provista de embolo para acción manual.

Figura 1. Peletizadora de accionamiento manual.

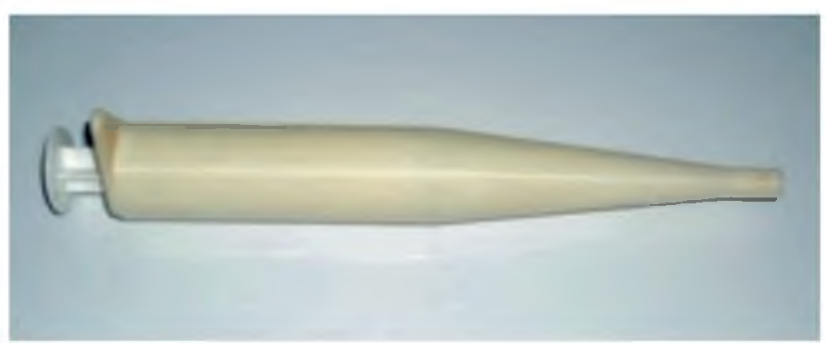


La compresión de la mezcla en el interior del dispositivo genera la salida de una tira cilíndrica de alimento peletizado que permite su corte a la longitud deseada.

Los dos alimentos elaborados y el alimento comercial, fueron caracterizados mediante análisis estadístico descriptivo y el color comparado mediante la utilización de coordenadas colorimétricas CieLab, Mediante ANOVA de una Vía, (NC=95\%) con el paquete estadístico Statgraphics 5.1 Plus, utilizando la metodología descrita por Padrón (2009), Sandoval y Prieto (2007) y Gutiérrez et al. (2011).

\section{Resultados}

La figura 2 presenta el Flujograma del proceso propuesto para la elaboración de los alimentos, las operaciones son en general las mismas para cualquier tipo de formulación, exceptuando que en el caso de componentes de gran tamaño como el caso de la cáscara de cacao, se hace necesario un troceado para facilitar el secado solar; para el caso de la pulpa de café, se incluyó un prensado mecánico con el fin de retirar lixiviados que dificultan el proceso de secado.

Figura 2. Diagrama de flujo del proceso de elaboración de alimentos

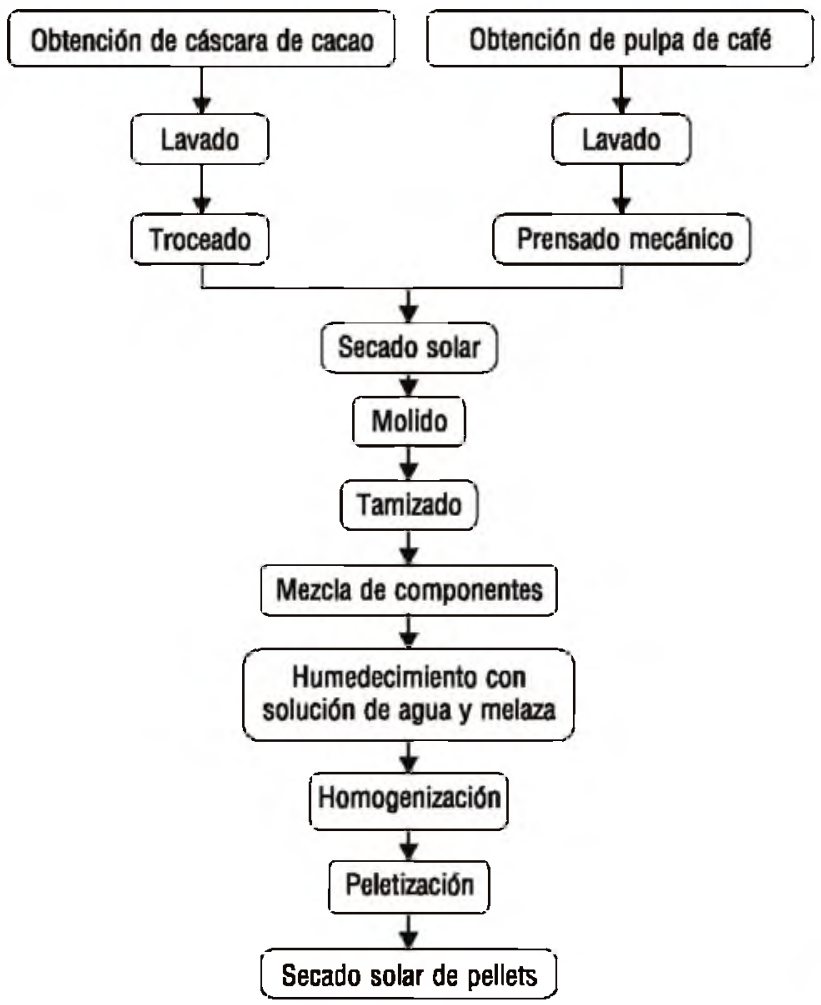

La figura 3, muestra los dos alimentos elaborados y el alimento comercial marca CONTEGRAL, que se utilizó como comparación, los alimentos elaborados presentan apariencia general similar al pellets comercial; las diferencias en color son notorias tal como se puede comprobar en la Tabla 2.

Figura 3. Pellets elaborados para T1, T2 y comercial.

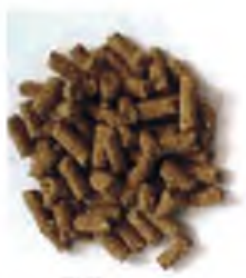

T1

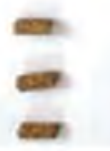

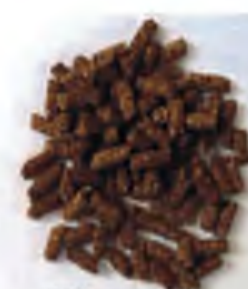

T2
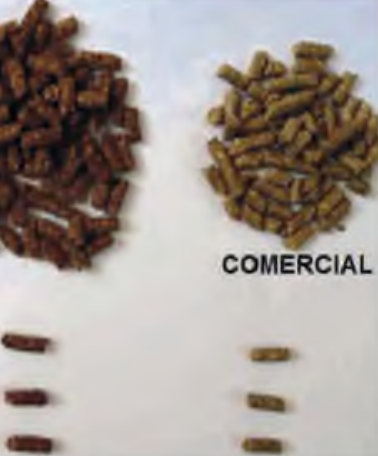

Tabla 2. Coordenadas colorimétricas en los tres alimentos evaluados

\begin{tabular}{llll}
\cline { 2 - 4 } & $T 1$ & $T 2$ & Comercial \\
\hline$L$ & $57,752^{\mathrm{a}}$ & $22,895^{\mathrm{b}}$ & $55,211^{\mathrm{a}}$ \\
\hline$a^{*}$ & $20,617^{\mathrm{a}}$ & $13,384^{\mathrm{b}}$ & $2,761^{\mathrm{c}}$ \\
\hline$b^{*}$ & $59,208^{\mathrm{a}}$ & $28,360^{\mathrm{b}}$ & $30,565^{\mathrm{b}}$ \\
\hline
\end{tabular}

Todos los tres alimentos presentan diferencias notorias en color, corroborado por las diferencias en las coordenadas colorimétricas encontradas; cabe destacar que el alimento T2, presenta un color más oscuro que los otros dos alimentos, verificado por el resultado del menor valor de luminosidad (L). El color como característica física en alimentos, está directamente relacionado con el nivel de aceptación del consumidor, sea humano o animal; en este estudio, las diferencias en color no presentaron impedimento para el consumo por los conejos.

En la Figura 4 se presentan el gráfico de medias para la luminosidad en donde se pueden apreciar las diferencias estadísticamente significativas entre los tratamientos evaluados; como puede verse, el Tratamiento T2 tiene una luminosidad más baja lo que le confiere un color más oscuro.

Figura 4. Gráfico de medias para luminosidad por tratamiento. $(\mathrm{NC}=95 \%)$

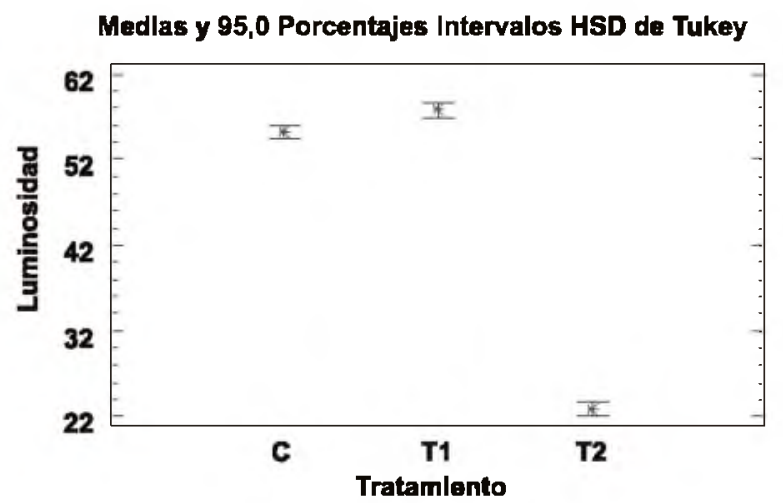


La Tabla 3 presenta la caracterización física de los tres alimentos evaluados, como puede notarse los diámetros y las longitudes de los tres alimentos son muy similares, indicando que el procedimiento definido en esta investigación satisface los requerimientos propuestos por Sánchez (2002). En cuanto a la densidad aparente, el alimento comercial tiene valores más altos, teniendo en cuenta que también tiene más altos contenidos de humedad.

Tabla 3. Caracterización física de los tres alimentos evaluados

\begin{tabular}{|c|c|c|c|c|c|c|c|c|}
\hline & \multicolumn{2}{|c|}{ Diómetro (cm) } & \multicolumn{2}{|c|}{ Longitud $(\mathrm{cm})$} & \multicolumn{2}{|c|}{$\begin{array}{l}\text { Densidad } \\
\text { aparente }(g r / m l)\end{array}$} & \multicolumn{2}{|l|}{$H b h(\%)$} \\
\hline & Promedio & $s$ & Promedio & $S$ & Promedio & $S$ & Promedio & $S$ \\
\hline$T 1$ (Cacao) & 0,5 & 0,01 & 1,34 & 0,11 & 0,26 & 0 & 6,57 & 0,06 \\
\hline$T 2$ (Café) & 0,48 & 0,01 & 1,35 & 0,11 & 0,26 & 0 & 7,73 & 0,15 \\
\hline T3 (Comercial) & 0,46 & 0,02 & 1,63 & 0,35 & 0,56 & 0 & 11,57 & 0,06 \\
\hline
\end{tabular}

\section{Conclusiones}

Se elaboró alimento artesanal para uso potencial en conejos con características de tamaño y forma similares al concentrado comercial CONTEGRAL ${ }^{\circledR}$, cuya estabilidad relacionada con la durabilidad del agregado fue satisfactoria.

El procedimiento para la elaboración del alimento concentrado corresponde a una metodología que puede ser utilizada de forma artesanal por familias campesinas, sin requerir la utilización de infraestructura costosa.

Las variaciones en color de los pelletsde los dos alimentos fabricados se debe a las características de los componentes, no constituyen en principio dificultades de aceptación por los conejos ya que en pruebas preliminares éstas no fueron rechazadas.

\section{Referencias Bibliográficas}

Veloz E., Diego Mauricio. (2011). Utilización de diferentes niveles de harina de algas de agua dulce en sustitución de la soya en la alimentación de conejos californianos desde el destete hasta el inicio de la vida reproductiva. Tesis Ing. Zootecnista, Facultad de ciencias pecuarias. Escuela superior politécnica de Chimborazo. Pp.96.
Ciprian, R., Hidalgo, V. (2007). Evaluación del tamaño de partícula y nivel de fibra en el concentrado para cuyes (Cavia Porcellus I.) en crecimiento. Anales Científicos. Universidad Nacional Agraria la Molina. Vol. 68. $\mathrm{N}^{\mathrm{B}}$ 1. Pp. 114-118.

Nieves D,. Cordero Y., Teran, O. y González C. (2004). Aceptabilidad de dietas con niveles crecientes de morera (Morus Alba) en conejos destetados. Zootecnia Trópica, Vol. 22, Número pp.202-209.

Nieves D., López D., Cadena, D. (2001). Alimentación de conejos de engorde con dietas basadas en materias primas no convencionales y suplementación con Tríchanthera gigantea. Venezuela.p7.

Quintero V., García G., y Peláez A. (2007). Evaluación de harina de Botón de Oro en dietas para conejos en etapa de crecimiento. Acta Agronómica Vol 56 n 4.Pp. 203-206.

Gutiérrez, N., Sarria, S., Castro, J. (2011). Evaluación de índices de madurez en guayaba pera (PsidiumGuajavaCv) cosechada en tres estados de madurez. En: $\Pi$ conferencia internacional en manejo poscosecha y calidad de productos hortícolas de interés en el trópico. Bogotá Colombia. Nov. 4 de 2011.

Bautista, E., Molina, N., Rodríguez, L. (1999). Pulpa de café ensilada en la alimentación cunícula en pulpa de café ensilada; producción, caracterización y utilización en la alimentación animal. Monografía Universidad Nacional Experimental de Táchira. Pp 156.

Bautista, E., Pernia, J., Barrueta, D. y Useche, M. (2005. Pulpa ecológica de café ensilada en la alimentación de alevines del hibrido cachamay (Colossomamacropomum X Viaractus Brachypomus. Revista científica FCV-LUZ. Vol. XV. N¹. Pp. 33-40.

Sandoval, Z. y Prieto, F. (2007). Caracterización de café cereza empleando técnicas de visión artificial. Revista facultad nacional de agronomía. Medellín. Vol. $60 \mathrm{~N}^{\circ} 2$. Pp 4105-4127.

Padrón. C. (2009). Sistema de visión computarizada y herramientas de diseño gráfico para la obtención de imágenes de muestra de alimentos segmentadas y promediadas en coordenadas Cielab. Agronomía Costarricense. Vol. 32 N². Pp. 283-301.

Sánchez C. (2002). Crianza y comercialización de conejos. Colección granja y negocios. Ed. RIPALME. Lima, Perú. 135p. Pág. 33, 39 